University of New Hampshire

University of New Hampshire Scholars' Repository

Applied Engineering and Sciences Scholarship

Applied Engineering and Sciences

$10-18-2007$

\title{
Teaching and learning in live online classrooms
}

Mihaela C. Sabin

University of New Hampshire, Manchester, mihaela.sabin@unh.edu

Bryan Higgs

Rivier College

Follow this and additional works at: https://scholars.unh.edu/unhmcis_facpub

Comments

(C) 2016, Association for Computing Machinery, Inc. This is the author's version of the work. It is posted here for your personal use. Not for redistribution. The definitive Version of Record was published in Proceedings of the 8th ACM SIGITE conference on Information technology education, https://dx.doi.org/.

\section{Recommended Citation}

Mihaela Sabin and Bryan Higgs, Teaching and learning in live online classrooms, Proceedings of the 8th ACM SIGITE conference on Information technology education, ACM, 2007, pp. 41-

This Article is brought to you for free and open access by the Applied Engineering and Sciences at University of New Hampshire Scholars' Repository. It has been accepted for inclusion in Applied Engineering and Sciences Scholarship by an authorized administrator of University of New Hampshire Scholars' Repository. For more information, please contact Scholarly.Communication@unh.edu. 


\section{Teaching and Learning in Live Online Classrooms}

\author{
Mihaela Sabin \\ University of New Hampshire Manchester \\ (former affiliation Rivier College) \\ 400 Commercial Street, Manchester, NH 03101 \\ (603)641-4144 \\ mihaela.sabin@unh.edu
}

\author{
Bryan Higgs \\ Rivier College \\ 420 South Main Street, Nashua, NH 03060 \\ (603) 897-8288 \\ bhiggs@rivier.edu
}

\begin{abstract}
Online presence of information and services is pervasive. Teaching and learning are no exception. Courseware management systems play an important role in enhancing instructional delivery for either traditional day, full-time students or non-traditional evening, party-time adult learners enrolled in online programs. While online course management tools are with no doubt practical, they limit, however, live or synchronous communication to "chat" rooms, whose discourse has little in common with face-to-face class communication. A more recent trend in online teaching and learning is the adoption and integration of web conferencing tools to enable live online classrooms and recreate the ethos of traditional face-to-face sessions.
\end{abstract}

In this paper we present the experience we have had with the adoption of the LearnLinc ${ }^{\circledR}$ web conferencing tool, an iLinc Communications, Inc. product. We have coupled LearnLinc with Blackboard $\AA$, for the online and hybrid computer science courses we offered in the past academic year in the evening undergraduate and graduate computer science programs at Rivier College. Twelve courses, enrolling over 150 students, have used the synchronous online teaching capabilities of LearnLinc. Students who took courses in the online or hybrid format could experience a comparable level of interaction, participation, and collaboration as in traditional classes.

We solicited student feedback by administering a student survey to over 100 students. The $55 \%$ response rate produced the data for this paper's study. We report on the study's findings and show students' rankings of evaluation criteria applied to hybrid and online instructional formats, with or without a web conferencing tool. Our analysis shows that students ranked favorably LearnLinc live sessions added to Blackboard-only online classes. In addition, how they learned in live online classrooms was found to be the closest to the hybrid class experience with regard to teaching practices they perceived as most important to them, such as seeking instructor's assistance, managing time on task, and exercising problem solving skills.

\section{Categories and Subject Descriptors}

K.3.1 [Computer Uses in Education]: Distance learning, Computer-managed instruction.

K.3.2 [Computer and Information Science Education]:

Computer science education, Information systems education.

General Terms: Design, Experimentation, Human Factors, Management, Performance.

Keywords: Synchronous (live) online instruction; online teaching and learning; online instructional technologies; web conferencing.

\section{INTRODUCTION}

Online presence of information and services is pervasive. Once static and passive, the navigation of online information repositories and operation of online services have become predominantly dynamic and interactive. Newspapers, digital libraries, commercial transactions, professional training, and standardized testing, to name just a few, have adopted an evergrowing plethora of online capabilities that have revolutionized the role and impact online services have on our everyday lives. Teaching and learning are no exception. The Sloan Consortium's fourth annual report on the state of online learning in U.S. higher education attests to the record online enrollment growth in 2006 [1].

Courseware management systems, such as Blackboard, play an important role in instructional delivery, whether serving the traditional education of full-time day students or non-traditional evening, part-time adult learners enrolled in online programs. The benefits of online course management are obvious. From posted course materials to timely announcements, mediated asynchronous group discussion boards, online examinations, or class grade books updated in real-time, course management systems improve dissemination of information and enable course participation outside the classroom [3][15]. The teaching experience with this kind of support has matured and best common practices have emerged [12][13]. However, standard web-based courseware limits live or synchronous communication to instant messaging, or "chat" rooms, whose discourse, restricted to a text-based format, has little in common with face-to-face class communication [10].

A more recent trend in online teaching and learning is the adoption and integration of web conferencing tools to enable live online classrooms. Featuring live audio and video, instant messaging, interactive white boards, synchronized browsing, and sharing of presentations and any other software applications, live 
online classrooms have the potential of emulating face-to-face classroom sessions and recreating the ethos of a traditional class [7][10][14].

The inventory of web conferencing products and services currently available is overwhelming and rapidly changing. Some of the vendors have tailored their tools to distance learning and live classrooms, such as Acrobat Professional Connect (from Adobe, formerly Macromedia Breeze), Centra Live (from Saba), Elluminate, LearnLinc (from iLinc), Live Classroom (from Wimba). The entire educational spectrum, ranging from $\mathrm{K}$ to 12 to higher education institutions, has shown interest in using these tools. However, forums specialized in scholarship of teaching and educational research, such as the Consortium for Computing Sciences in Colleges and the ACM special interest groups in Computer Science and Information Technology education, have presented with very few studies whose research topics cover live, synchronous online instruction. Given that the landscape of higher education is significantly and consistently affected by the ever increasing role of online teaching and learning, we find it important to examine how widely acknowledged drawbacks, such as lack of personal contact and absence of social interactions [2] [9] [11], can be overcome by enhancing the online environment with a live component obtained through the use of web conferencing tools.

In this paper we present the experience we have had with the adoption of the LearnLinc web conferencing tool, an iLinc Communications, Inc. product. We have coupled LearnLinc with Blackboard for the online and hybrid (or blended) computer science courses we offered in the past academic year in our department. Twelve undergraduate and graduate courses counting an enrollment of over 150 had the synchronous online teaching capabilities of LearnLinc. Eighty students on average per semester took courses in the online and hybrid format, and approximately two thirds of them had direct experience with the new ways web conferencing facilitates classroom interaction, participation, and collaboration. The feedback we received from sixty students has been positive. Students have acknowledged that their learning experience in online classes improved with the use of live online sessions. These findings confirm our hypothesis that the increase of course enrollments and program majors opting for online format is due in part to student satisfaction with this new format.

\section{THE CONTEXT}

In order to increase enrollments in the department computingrelated programs (undergraduate CS and IT and graduate CS, CIS, and certificates), CS faculty conducted a thorough curricular revision in the spring of 2006. The revision considered both curricular updates and the introduction of new instructional formats. Special emphasis was given to the design of new courses and the integration of the newest computing technologies in teaching the programs' courses. The curriculum revision was informed by a thorough analysis of the current occupational outlook and computing specializations and skills potential employers find most relevant.

A second significant change was the adoption of new instructional delivery formats, fully online and hybrid (or blended, which combines weekly face-to-face classes with the use of a course management system, in our case Blackboard). The graduate programs, masters and certificates, have fully online formats in addition to face-to-face. The undergraduate degree completion programs have online formats too, since students in these programs transfer in between 60 to 90 credits, in which case the courses they take to fulfill program requirements are the online courses in the major.

Essential to the decision of offering an online delivery format for the major courses was the consideration of diversifying the programs delivery formats with the addition of online instructional tools that would enable, to some extent, the kind of class communication and interaction that are typical of a face-toface environment. We were particularly interested in an online environment that would enable hands-on teaching and learning, facilitate productive and focused participation, support the development of problem-solving skills, and create opportunities for students to interact and work together. We concur that a course management system, such as Blackboard, is very useful for disseminating and exchanging course materials and student work submissions, as well as supporting asynchronous communication via announcements posting and discussion boards [3][15]. However, it inherently limits the transfer of effective practices historically linked to a traditional classroom [8], where students and instructor belong to a social entity governed by direct interaction in real time, unobstructed by any kind of technological mediation. Although there are accounts of successfully recreating a face-to-face ethos with exclusively Blackboard-based means, such as asynchronous discussions, our own reservations have been confirmed by studies that point to important problems an online class continues to face [2] [9] [11].

More convincingly, despite having Blackboard "chat rooms" listed as substitutes for synchronous office hours by many online courses and programs, we could not find any compelling study that reports on the merit of text-messaging for online education, or on any kind of emerging practices with this very modern and unusual instructional tool. We understand why the addition of synchronous online activities to the online environment may more readily facilitate the implementation of good teaching practices. Educational research has identified this kind of practices, such as contact between students and faculty, reciprocity and cooperation among students, and active learning [8]. The implementation of these practices though should go far beyond online "chatting" [10].

Current web conferencing systems, especially those tailored to classroom instruction, have suitable tools for creating a live classroom with remote participants. Computing programs at Northwest Missouri University [10], Macquarie University in Australia [4][5][6][7], and George Mason University [14] have complemented asynchronous online education with synchronous sessions in their programs by using Saba's Centra Live, Adobe's Acrobat Connect Meeting, and an open source product entirely developed in the CS Department at George Mason University, Network EducationWare (NEW). We examined three web conferencing platforms, Acrobat Connect Meeting (formerly Macromedia Breeze at the time of our evaluation), Elluminate Live!, and LearnLinc. In the spring of 2006 we conducted trial testing with Elluminiate Live! and LearnLinc. Cost effectiveness constraints and quality of service with the trial versions determined our choice for LearnLinc from iLinc Communications, Inc. The college purchased 30 concurrent LearnLinc seats in the summer of 2006, which represent the 
maximum capacity of a live session we can open for any of the scheduled courses. iLinc servers host the sessions and make available a downloadable client that instructors and students can access from a Web site specifically set up for our school.

All CS courses scheduled for the academic year 2006-2007 were offered in hybrid and online format in a cross-listed fashion. This means that the same course, with the same instructor, registered students who chose to come to the scheduled weekly classes (hybrid format), as well as students who took the course completely online (online format). Due to the novelty of the instructional formats, we did not expect large enough enrollments to allow us to divide the two different types of audiences into two separate sections. It is important to point out that cross-listing hybrid and online formats for the same course puts a considerable burden on instructors with regard to course administration. On the other hand, the direct interaction with students who attend hybrid classes provided immediate feedback about topic coverage, assigned work, and course pace, which could be immediately used to adjust the online delivery of the same class. Two thirds of the scheduled courses used LearnLinc. The live sessions were paired up with the scheduled hybrid classes. Online students had the opportunity to join these LearnLinc sessions remotely. All sessions were recorded and all students could benefit from playing the recordings for the purpose of reviewing what was taught and covered in a particular class.

Table 1. Computer Science course enrollments in 2006-2007

\begin{tabular}{|l|r|r|r|r|r|r|}
\hline & \multicolumn{3}{|c|}{ Fall 2006 } & \multicolumn{2}{c|}{ Spring 2007 } \\
\hline \multicolumn{1}{|c|}{ Courses } & $\begin{array}{c}\text { No. of } \\
\text { courses }\end{array}$ & \multicolumn{2}{|c|}{ Enrollments } & $\begin{array}{c}\text { No. of } \\
\text { courses }\end{array}$ & \multicolumn{2}{|c|}{ Enrollments } \\
\hline $\begin{array}{l}\text { U lower- } \\
\text { level }\end{array}$ & 3 & 34 & 2 & 30 \\
\hline $\begin{array}{l}\text { U upper- } \\
\text { level \& G }\end{array}$ & 7 & & 97 & 9 & & 104 \\
\hline Totals & $\mathbf{1 0}$ & & $\mathbf{1 3 1}$ & $\mathbf{1 1}$ & & $\mathbf{1 3 4}$ \\
\hline \multicolumn{2}{|c|}{$\begin{array}{c}\text { Undergrad \& } \\
\text { Grad Enrollments }\end{array}$} & $\mathbf{1 1 1}$ & $\mathbf{2 0}$ & & $\mathbf{8 4}$ & $\mathbf{5 0}$ \\
\hline
\end{tabular}

We analyzed the course enrollments and numbers of matriculated students in the undergraduate $(\mathrm{U})$ and graduate $(\mathrm{G})$ courses in the academic year 2006-2007 (Table 1 and Table 2). Both semesters scheduled almost the same number of courses (ten in fall and eleven in spring) leading to very similar enrollments (131 and 134, respectively (Table 1)). The distribution of enrollments over hybrid and online formats, however, differed. While hybrid format enrollment decreased by $24 \%$, online enrollment increased by $40 \%$ from fall to spring.

Corresponding to the enrollments situation, the number of registered students in each semester was almost the same, 83 in fall and 82 in spring (Table 2). Following the enrollment course pattern observed for the hybrid and online formats, the number of students registered in online courses increased by $50 \%$ from fall to spring.
Table 2. Evening undergraduate and graduate students

\begin{tabular}{|c|c|c|c|c|}
\hline & \multicolumn{2}{|c|}{ Fall 2006} & \multicolumn{2}{|c|}{ Spring 2007} \\
\hline Undergraduate students & & 25 & & 26 \\
\hline Graduate students & & 58 & & 58 \\
\hline Totals & & 83 & & 82 \\
\hline \multirow{2}{*}{$\begin{array}{l}\text { Undergrad \& Grad } \\
\text { Students }\end{array}$} & Hybrid & $\begin{array}{l}\text { On- } \\
\text { line }\end{array}$ & Hybrid & $\begin{array}{l}\text { On- } \\
\text { line }\end{array}$ \\
\hline & 69 & 14 & 54 & 28 \\
\hline
\end{tabular}

Although a two-semester sequence is the shortest time span to inform a comparative analysis of how student preference for a particular format has changed over time, the outcome of positive percentages in double digits seems to confirm that the demand for online courses and programs is real. In addition, we hypothesize that this demand may be matched by student confidence in and satisfaction with the online format we have delivered for our programs.

The study we present in this paper was prompted by the promising results we have seen of increased enrollments in general and growing interest in online courses in particular. In the following sections we describe the research method we applied to obtain student feedback on course delivery format. Based on the data collected we present some of the relevant observations pertaining to teaching and learning in online courses and live classrooms. We discuss these results and conclude with a summative account of this study and some future research directions.

\section{RESEARCH METHOD}

We solicited student feedback by conducting a survey in June 2007. The survey instrument was designed to gauge student evaluation of two representative instructional formats, hybrid (or face-to-face with Blackboard support) and online (delivered entirely through Blackboard). Two thirds of the courses scheduled in 2006-2007 used LearnLinc to set up live sessions coupled with both hybrid and online classes. The live sessions were scheduled at the time the face-to-face classes for the hybrid courses were scheduled. Four possible instructional formats resulted from combining hybrid and online with live LearnLinc (LL) sessions (hybrid, hybrid+LL, online, and online+LL). The survey was sent out to 107 undergraduate and graduate computer science students in the department programs. 60 students (a 55\% response rate) completed and returned their surveys.

The survey has eight parts and a total of 34 questions. Part I gathered student information (including program of study and familiarity with any of the four instructional formats in question). The last part opened the door for student availability for followup interviews and, possibly, a focus group. With the exception of Part VII, which provided the opportunity to respond to six openended questions, the remaining five parts, Part II to Part VI, used a 1 to 5 scale for 21 questions geared towards overall evaluation of all formats, as well as individual format evaluation of hybrid, online, and web conferencing.

We took into the account that student exposure to and familiarity with the instructional formats in question varied. However, we were interested in student perception of how each of the four 
formats facilitates learning, whether student perception was based on direct experience with classes taken in our programs in 20062007, or was influenced by other experiences (classes taken elsewhere, workplace training, professional development, or personal readings on the topic online instruction).

Part II of the survey focused on how effectively each of the formats implements some of the good practices in education, as summarized in the notable seven principles formulated by Chickering and Gamson [8]. Attention was given to evaluation criteria that relate to active learning, time on task, cooperation among students, and contact between students and faculty (Table $3)$.

Table 3. Instructional format evaluation criteria

\begin{tabular}{|l|}
\hline Q1 Get to know and interact with peers during and outside class. \\
\hline Q2 Establish professional connections with peers. \\
\hline Q3 Seek assistance with assigned homework and projects. \\
\hline $\begin{array}{l}\text { Q4 Manage learning and study time, avoid procrastination, and } \\
\text { meet course deadlines. }\end{array}$ \\
\hline $\begin{array}{l}\text { Q5 Communicate with the instructor on personal issues that have } \\
\text { interfered with learning in the course. }\end{array}$ \\
\hline Q6 Practice and demonstrate oral communication skills. \\
\hline Q7 Practice and demonstrate problem solving skills. \\
\hline Q8 Feel comfortable about course examinations. \\
\hline Q9 Get a good sense of the class community and benefit from it. \\
\hline
\end{tabular}

We were also interested in knowing how students rank these questions according to each question's perceived importance.

The questions in Parts III to $\mathrm{V}$ were aimed at a particular instructional format and thus attempted to identify formatdependent benefits. These questions are shown in Table 4, 5, and 6.

Table 4. Hybrid format evaluation criteria

\#1 Have direct interaction with the instructor.

\#2 Participate in class activities.

Table 5. Online format evaluation criteria

\#1 Overcome geographical distance which makes campus commute impossible for me.

\#2 Have the convenience of no campus commute.

\#3 Take advantage of a flexible academic schedule.

\#4 Solve scheduling conflicts with other classes.

Table 6. Web conferencing evaluation criteria

\#1 Participate in lab activities.

\#2 Use recordings to review class material.

\#3 Use recordings to make up effectively for missed classes.

Students were also asked to rank the level of technical difficulty they experienced with Blackboard and LearnLinc, and the level of difficulty encountered while adjusting their learning to the online format. Finally, Part VII collected some concluding reflections prompted by six open-ended questions (Table 7).

Table 7. Concluding reflections

\#1 What format works the best for you?

\#2 Are there other advantages you have experienced with the format of your choice?

\#3 Are there other drawbacks of the instructional formats surveyed here?

\#4 Do you have any suggestions for how web conferencing can be used more effectively to enhance learning?

\#5 Is the online format suitable to teaching and learning computer science and information technology?

\#6 Anything else you would like to share?

\section{RESULTS AND DISCUSSION}

\subsection{Salient Features of Instructional Formats}

The evaluation of the hybrid format confirmed that students regard their direct interaction with the instructor and participation in class activities as strong benefits of this mode of delivery. Table 8 shows score average (Avg) and standard deviation (SD) results from assessing the hybrid format. Student agreement on the merit of the two benefits of the hybrid format (high scores of 4.42 and 4.27 ) is very consistent (low standard deviation values of 0.93 and 0.98 ). We note that the opportunity to directly interact with the instructor weighs slightly more than student expressed interest in class participation.

Table 8. Hybrid format evaluation results

\begin{tabular}{|c|l|c|c|}
\hline$\#$ & \multicolumn{1}{|c|}{ Evaluation Criterion } & Avg & SD \\
\hline 1 & Have direct interaction with instructor & 4.42 & 0.93 \\
\hline 2 & Participate in class activities & 4.27 & 0.98 \\
\hline & Total Results & 4.35 & 0.96 \\
\hline
\end{tabular}

It is well known that the popularity of the online format is in large part due to the convenience it provides with regard to school location and class schedule constraints. The "anyplace, anytime" model of non-traditional, part-time adult learners' preference for educational preparation is exactly what the online format implements. In some cases, some scheduling constraints persist if instant messaging-based office hours or other types of synchronous sessions are required.

Table 9 and Figure 1 show how students ranked the online format benefits listed in the survey.

We observe that time, rather than location, weighs more in student preference for the online format. Schedule flexibility ranks the highest (4.10) and has the lowest standard deviation (0.88). Avoiding scheduling conflicts ranks second, although student agreement on it is more dispersed (1.26 standard deviation). 
Table 9. Online format evaluation results

\begin{tabular}{|c|l|c|c|}
\hline$\#$ & \multicolumn{1}{|c|}{ Evaluation Criterion } & Avg & SD \\
\hline 1 & $\begin{array}{l}\text { Take advantage of a flexible academic } \\
\text { schedule. }\end{array}$ & 4.15 & 0.90 \\
\hline 2 & $\begin{array}{l}\text { Solve scheduling conflicts with other } \\
\text { classes. }\end{array}$ & 3.65 & 1.31 \\
\hline 3 & $\begin{array}{l}\text { Have the convenience of no campus } \\
\text { commute. }\end{array}$ & 3.65 & 1.67 \\
\hline 4 & $\begin{array}{l}\text { Overcome geographical distance which } \\
\text { makes campus commute impossible for me. }\end{array}$ & 3.31 & 1.92 \\
\hline & Total Results & 3.69 & 1.52 \\
\hline
\end{tabular}

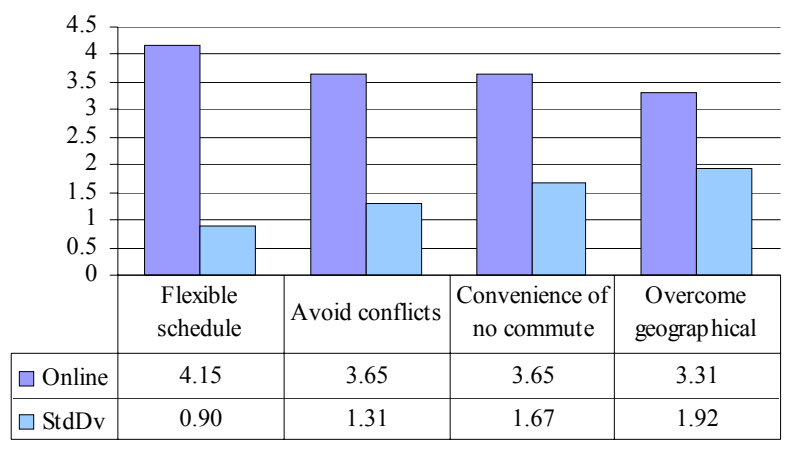

Figure 1. Graphical representation of results in Table 9

Fewer students perceive the convenience of no commute or overcoming geographical distance that would have made their commute impossible. The standard deviations in these cases are much higher. We attribute this finding to the low number of students who are not local to the college area, or whose work special commitments, such as business travel, would prevent college commute. This may change as our programs' online component will recruit students from a much larger geographical area.

The web conferencing sessions, which we added to two thirds of the program's classes and coupled with both hybrid and online, were perceived to be very beneficial for making available the actual class content through LearnLinc recordings (Table 10 and Figure 9). This feature was acknowledged as particularly useful when students missed scheduled hybrid and/or synchronous live sessions. It also shows the advantage of reviewing class materials and activities at a later time. Fewer students appreciated the benefit of live sessions to facilitate participation in lab activities. Student feedback on all these three evaluation criteria was very consistent, almost the same, with a fairly low standard deviation.

We should point out that making LearnLinc recordings was initiated in the second semester and was largely prompted by students. They did not hesitate to give us immediate positive feedback when the recording feature was enabled for all the LearnLinc sessions.

The use of live sessions for lab activities was limited to two classes in fall and three classes in spring. Two instructors involved with teaching undergraduate programming courses in the lab made use of the application sharing feature of LearnLinc to let students take turns in doing and demonstrating their programming with the BlueJ system (a public domain Java pedagogical interactive development environment). The reduced scope in utilizing LearnLinc for lab activities might explain student lower evaluation of this feature.

Table 10. Web conferencing evaluation results

\begin{tabular}{|c|l|c|c|}
\hline$\#$ & \multicolumn{1}{|c|}{ Evaluation Criterion } & Avg & SD \\
\hline 1 & $\begin{array}{l}\text { Use recordings to make up effectively for } \\
\text { missed classes. }\end{array}$ & 4.31 & 1.01 \\
\hline 2 & Use recordings to review class material. & 4.09 & 1.01 \\
\hline 3 & Participate in lab activities. & 3.72 & 1.07 \\
\hline & Total Results & 4.04 & 1.05 \\
\hline
\end{tabular}

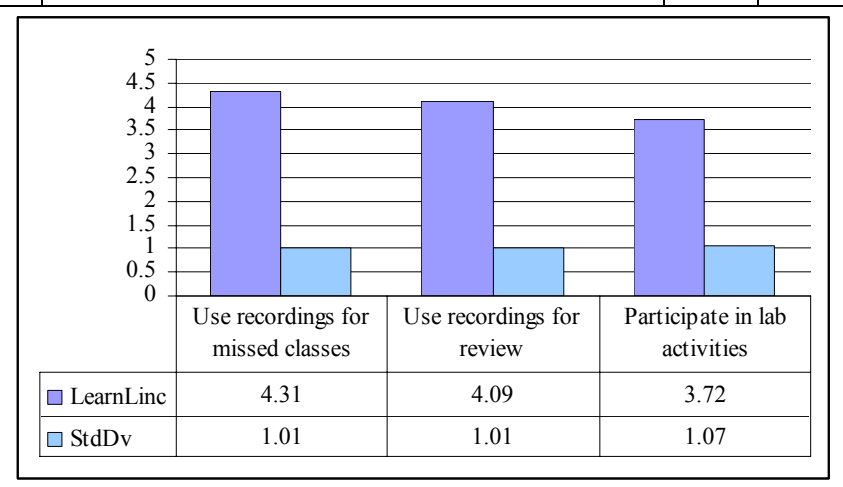

Figure 2. Graphical representation of results in Table 10

\subsection{Technology Use Feedback}

The levels of technical difficulty in using either Blackboard or LearnLinc were fairly low (Figure 3). The level of difficulty encountered by students adjusting to the online format shows a slightly higher score average, 2.41, within the same range of student consensus as shown for the other two questions and measured by a standard deviation of 1.11 .

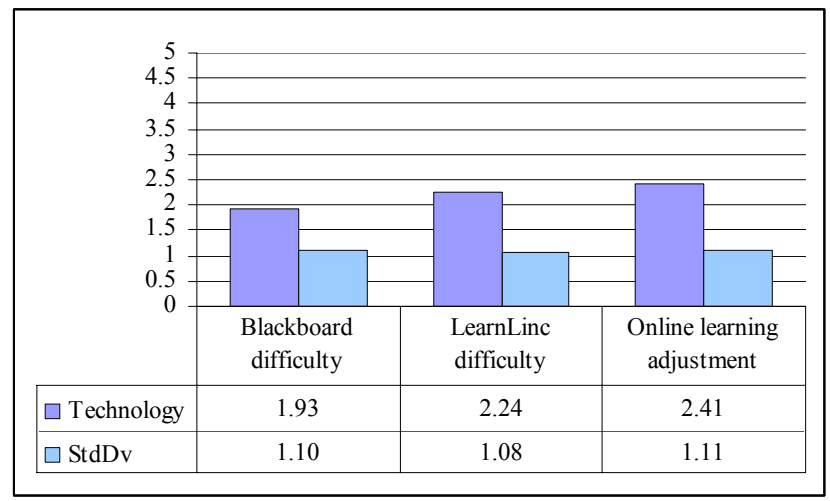

Figure 3. Technology use feedback results

These results match our expectations. Students in CS and IT programs have the skills necessary to adapt to, utilize, and manage computing technologies in general. Neither Blackboard nor LearnLinc appears to be an exception to this. The adjustment to technology-mediated online learning is of a different sort and involves many other aspects which are not specific to technology, per se. 


\subsection{Common Features Assessed Across Instructional Formats}

Student ranking of the set of evaluation criteria we used across all four instructional formats (Q1 to $\mathrm{Q} 9$ listed in Table 3) produced C1 to C9 list (Table 11) of the sorted criteria (descending order of score averages) by perceived importance. The graphical representation of these results (Figure 4) pairs up student ratings $(\mathrm{C \#})$ with the corresponding evaluation criteria $(\mathrm{Q} \#)$.

Table 11. General evaluation criteria ordered by perceived importance, $\mathrm{C} 1$ to $\mathrm{C} 9$, from highest to lowest

\begin{tabular}{|c|l|c|c|}
\hline$\#$ & \multicolumn{1}{|c|}{ Evaluation Criterion } & Avg & SD \\
\hline C1 & Seek assistance with assigned work (Q3) & 4.35 & 0.87 \\
\hline C2 & Manage learning and study time (Q4) & 4.24 & 0.93 \\
\hline C3 & $\begin{array}{l}\text { Practice and demo problem solving skills } \\
\text { (Q7) }\end{array}$ & 4.20 & 1.02 \\
\hline C4 & $\begin{array}{l}\text { Communicate with instructor on personal } \\
\text { issues (Q5) }\end{array}$ & 4.09 & 1.01 \\
\hline C5 & $\begin{array}{l}\text { Feel comfortable about the course exams } \\
\text { (Q8) }\end{array}$ & 4.07 & 1.06 \\
\hline C6 & $\begin{array}{l}\text { Practice and demo oral communication } \\
\text { skills (Q6) }\end{array}$ & 3.94 & 0.94 \\
\hline C7 & $\begin{array}{l}\text { Get a good sense of the class community } \\
\text { (Q9) }\end{array}$ & 3.89 & 0.95 \\
\hline C8 & Get to know and interact with peers (Q1) & 3.74 & 1.05 \\
\hline C9 & Establish professional connections (Q2) & 3.61 & 0.98 \\
\hline & Total Results & 4.02 & 1.00 \\
\hline
\end{tabular}

The perceived benefits score from 4.35 to 3.61 , averaging 4.02. The standard deviation is 1.00 on average, within a fairly tight range of 0.87 to 1.06 .

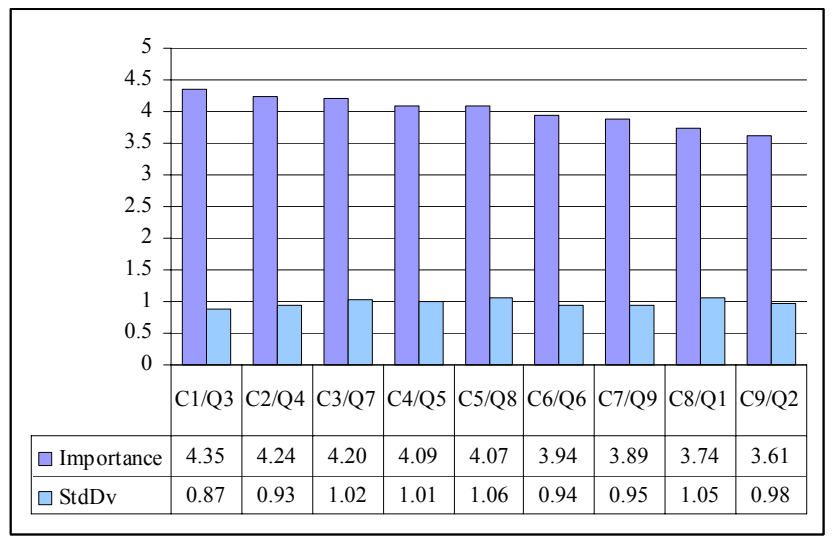

Figure 4. Graphical representation of results in Table 11

Students determined that, most importantly, an instructional format effectively allows learners to seek assistance from the instructor with assigned homework and projects (4.35). Support for managing time on task (4.24) and exercising problem solving skills (4.20) follow in the evaluation criteria ordered according to perceived importance. We point out that two criteria on which students share the most consistent agreement (with lowest standard deviations of 0.87 and 0.93 ) are also the highest ranked.
The lowest ranked teaching and learning objectives a format would be expected to implement are about peer dynamics in a class, such as establishing professional connections (3.61), knowing and interacting with peers (3.74), and perceiving the class as a learning community (3.89). Developing oral communication skills is also placed in the second half of the criteria importance ordering (3.94).

The instructional aspects on which students seem to share a "borderline" agreement, with rankings of 4.09 and 4.07 - closest to the overall ranking average of 4.02, regard communication with instructor on personal issues and level of comfort with course examinations.

Guided by the student perceived importance of the format evaluation criteria, we show in Figure 5 and Figure 6 how each format was ranked for two of the top criteria: seek assistance with work (perceived as most important $-\mathrm{C} 1 / \mathrm{Q} 3$ in Figure 5), and develop problem solving skills, (of the third highest importance $\mathrm{C} 3 / \mathrm{Q} 7$ in Figure 6).

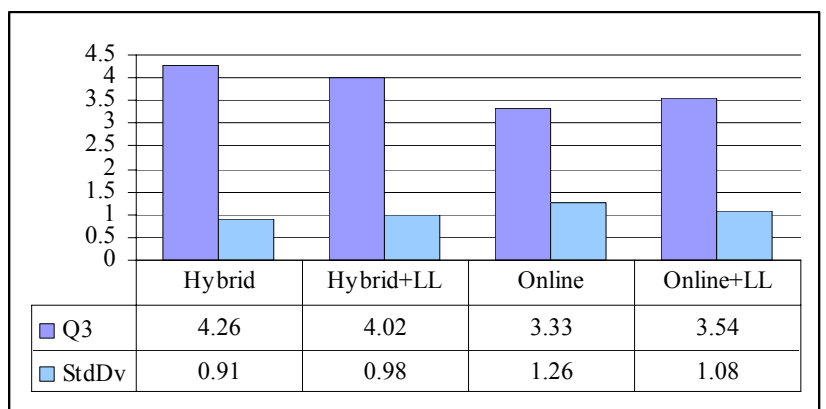

Figure 5. Evaluation results of how effectively instructional formats allow students to seek assistance with work

The four formats are hybrid and online with or without integrating LearnLinc (LL) sessions, and, consequently, labeled Hybrid, Hybrid+LL, Online, and Online+LL.

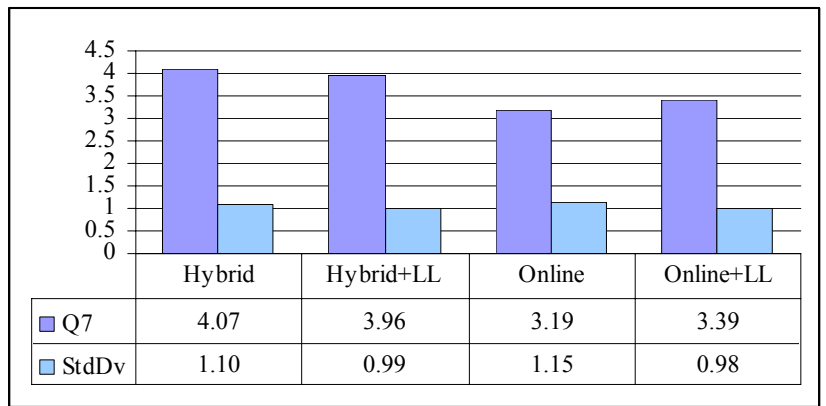

Figure 6 Evaluation results of how effectively instructional formats allow students to exercise problem solving skills

Both cases show similar results. The hybrid format is a winner, with scores above 4 , followed closely by hybrid with LeanrLinc sessions. The two online formats are comparable to each other, but online with LearnLinc scores higher, closer to 3.5.

The pattern of ranking the four formats for these two particular criteria is replicated for all the other criteria. In Figure 7 we show comparative results of the instructional formats ordered by the perceived importance of the evaluation criteria. Hybrid formats score higher than online formats. However, online with LeanrLinc consistently wins over online with Blackboard only. 


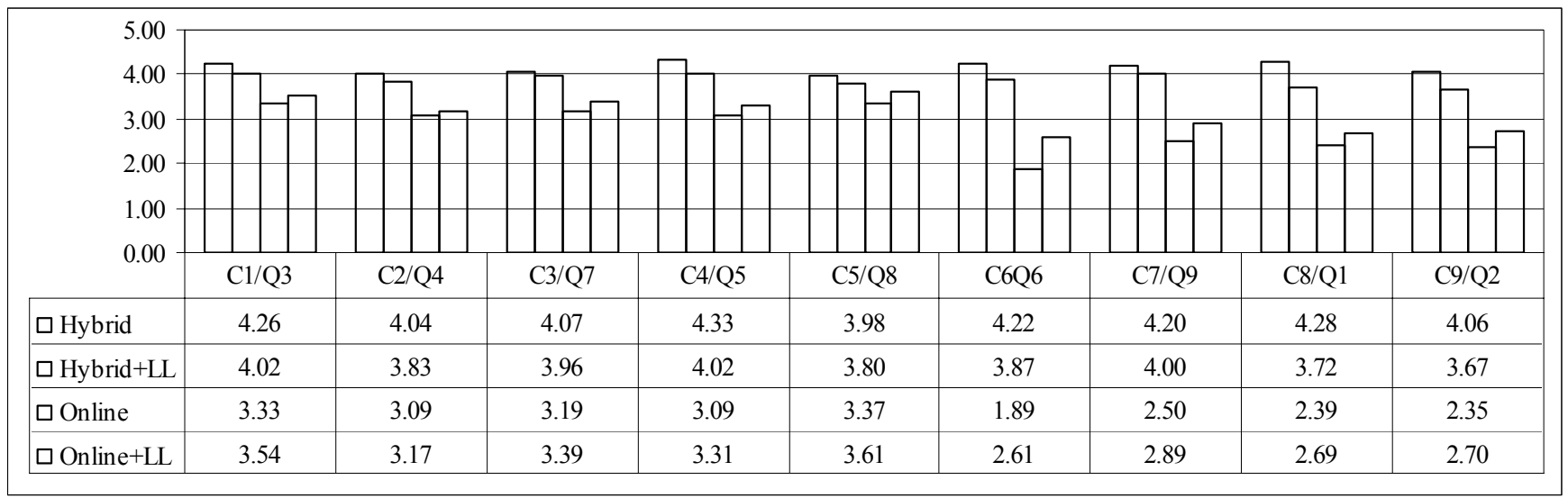

Figure 7. Comparative results across evaluation criteria ordered by perceived importance and applied to all instructional formats

Although the online format with LearnLinc does not reach or exceeds performance levels recorded by the hybrid formats, it is encouraging to see its gain over traditional online. We note that student perception of the merit of each format is influenced by both their choice of a particular instructional delivery mode and their familiarity with it, whether acquired through direct academic experience or from other sources. We note that the number of students enrolled in online classes (two thirds of which have used LearnLinc) doubled from fall to spring (see Section 2). However, the students taking hybrid classes continued to hold the majority ( $83 \%$ in fall and $54 \%$ in spring).

Another interesting finding is the pattern of the relative gain of the hybrid format over online with LearnLinc.

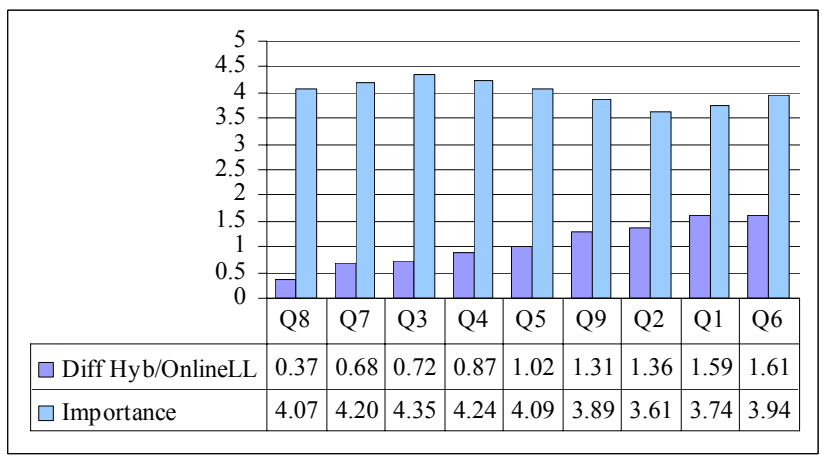

Figure 8. Relative gain of hybrid over online with LearnLinc (in increasing order) versus importance ranking

In Figure 8 we show the performance gain of the hybrid format over online with LearnLinc (see first set of graphic bars, labeled DiffHyb/OnlineLL). Notably, with the exception of the last criterion (Q6 - oral communication), online with LearnLinc scores much closer to hybrid on the top three evaluation criteria (C1/Q3 - seek assistance, C2/Q4 - manage study time, and C3/Q7 - problem solving skills). The difference between these formats increases for less important evaluation criteria $(\mathrm{C} 7 / \mathrm{Q} 9$ - sense of community and C9/Q2 - professional connections). The smallest difference between hybrid and online with LearnLinc (0.37) occurs for Q8 criterion, "feel comfortable about course exams", which has the median place (C5) within the nine evaluation criteria. Although the highest gain online with LearnLinc has over Blackboard-only online is on oral communication skills (Q6), the same criterion places online with LearnLinc furthest apart from hybrid.

These observations confirm what we have experienced in teaching our classes with these formats. The most significant advantage live online sessions have is their effectiveness in implementing online hands-on and class participation activities. Teaching and learning in live online classrooms is a new endeavor for both students and teachers. There are no known practices that have been already tested and proved to work. Transferring widely accepted good practices from a face-to-face environment into online with web conferencing tools is not a simple, direct, and linear process. The underlying premises, however, are the same. The more authentic student and instructor interaction is, not limited to a specific type of discourse, like asynchronous bulletin boards, the more engaged, shared, and effective class learning become. Take for example the difference it makes for students to know, while taking an examination, that the instructors and peers participate together in a live session. It almost removes the online barrier and brings the class the closest to a face-to-face one.

We also note that a face-to-face environment possesses dynamics in which everybody is inherently "fluent" with regard to experiencing the class community, interacting with peers, and establishing professional connections. A syllabus tailored to a face-to-face format most likely spells out such dynamics in a minimal way, if any. The online format with live sessions, on the other hand, has much more to compensate for when the face-toface cues are totally absent and the medium which potentially might offer a substitute is such a novelty to teacher and student alike. We hypothesize that much more practice with this new technology, in the academic realm and elsewhere, and extensive educational research are needed to lay the foundations of how live online sessions can be used most effectively.

\section{CONCLUSION AND FUTURE WORK}

We conclude from the results of this survey that our students have received the addition of a web conferencing component to our programs' hybrid and online courses in a positive way. In particular, there appears to be widespread agreement among students on the benefits of recording class sessions using the web conferencing tool; they have actively used those recordings to review and/or "time-shift" the viewing of the topics covered in those classes. The practice of recording classroom sessions necessitated replacing physically writing or drawing on the 
classroom whiteboard with a mechanism, provided by the web conferencing tool, for capturing such activities electronically. While many of the instructors found this to be rather limiting (drawing with a mouse leaves much to be desired), the end result was nonetheless valued by the students.

Based on our experiences with this survey, we believe we can improve the structure of future surveys. More can be learned from clearly separating out the results for two sets of student backgrounds: those who have a good familiarly with the various instructional formats, and those who do not. We will most likely find a way to put our improved surveys online, so that we may more conveniently capture and analyze the results.

In addition, we plan to survey our instructors (and colleagues elsewhere) in a similar way, and try to capture their potentially different perspectives. Another source of data for further researching this topic are the student answers to the open-ended questions in the survey. We plan to follow up on their comments with individual interviews and possibly a focus group.

Finally, the analysis of student satisfaction with various instructional formats should be coupled with the assessment of learning outcomes recorded for individual format-related groups. Overall, the distribution of student performance in the hybrid and online formats we offered in our programs showed very similar patterns. Identical course assessment tools (homework assignments, projects, tests, presentations) were used in both formats of the same course. However, a carefully designed assessment of student learning outcomes should be conducted to inform us about the instructional quality of live online classrooms.

\section{ACKNOWLEDGMENTS}

This study would not have been possible without our students' contribution and feedback. Good teaching and learning knows no separation between teachers and learners. We are grateful to the College for funding the acquisition of iLinc's tool suites and supporting the implementation of the department's online programs.

\section{REFERENCES}

[1] Allen, I.E. and Seaman, J. Making the grade: online education in the United States, 2006. Sloan Consortium, 2006. At http://www.sloan-

c.org/publications/survey/pdf/making_the_grade.pdf. Accessed Juy 2007.

[2] Aman, J.R. and Shirvani, S. 2006. Dick and Jane online: considering online coursework. Journal of Computing Sciences in Colleges, 21, 3 (Feb. 2006), 131-138.

[3] Bhagyavati, Kurkovsky, S., and Whitehead, C. C. 2005. Using asynchronous discussions to enhance student participation in CS courses. In Proceedings of the 36th SIGCSE Technical Symposium on Computer Science Education (St. Louis, Missouri, USA, February 23 - 27, 2005). SIGCSE '05. ACM Press, New York, NY, 111-115.

[4] Bower, M. and Richards, D. 2005. The impact of virtual classroom laboratories in CSE. In Proceedings of the 36 th
SIGCSE Technical Symposium on Computer Science Education (St. Louis, Missouri, USA, February 23 - 27, 2005). SIGCSE '05. ACM Press, New York, NY, 292-296.

[5] Bower, M. 2006. Virtual classroom pedagogy. In Proceedings of the 37th SIGCSE Technical Symposium on Computer Science Education (Houston, Texas, USA, March 03 - 05, 2006). SIGCSE '06. ACM Press, New York, NY, 148-152.

[6] Bower, M. 2006. A learning system engineering approach to developing online courses. In Proceedings of the 8th Australian Conference on Computing Education - Volume 52 (Hobart, Australia, January 16 - 19, 2006). D. Tolhurst and S. Mann, Eds. ACM International Conference Proceeding Series, vol. 165. Australian Computer Society, Darlinghurst, Australia, 45-54.

[7] Bower, M. 2007. Groupwork activities in synchronous online classroom spaces. In Proceedings of the 38th SIGCSE Technical Symposium on Computer Science Education (Covington, Kentucky, USA, March 07 - 11, 2007). SIGCSE '07. ACM Press, New York, NY, 91-95.

[8] Chickering, A.W. and Gamson, Z.F. 1987. Seven principles for good practice in undergraduate education. $A A H E$ Bulletin, 39, 7, 3 - 7.

[9] Grandon, E. E., Alshare, K., and Kwun, O. 2005. Factors influencing student intention to adopt online classes: a crosscultural study. J. Comput. Small Coll. 20, 4 (Apr. 2005), 4656.

[10] Heeler, P. and Hardy, C. 2005. A preliminary report on the use of video technology in online courses. J. Comput. Small Coll. 20, 4 (Apr. 2005), 127-133.

[11] Matzen, R and Alrifai, R. 2006. Teaching computing on the web: a survey of computer science faculty. Journal of Computing Sciences in Colleges, 21, 4 (Apr. 2006), 76 - 82.

[12] Nelson, M., Bhagyavati, Miles, G., Settle, A., Shaffer, D., Watts, J., and Webber, R. P. 2005. Online teaching practices (both best and worst). J. Comput. Small Coll. 21, 2 (Dec. 2005), 223-230.

[13] Pelz, B. 2004. (My) three principles of effective online pedagogy. Journal of Asynchronous Learning Networks, 8, 3 (June 2004). Sloan Consortium. At http://aln.org/publications/jaln/v8n3/v8n3_pelz.asp. Accessed July 2007.

[14] Pullen, J. M. 2006. Scaling up a distance education program in computer science. In Proceedings of the 11th Annual SIGCSE Conference on innovation and Technology in Computer Science Education (Bologna, Italy, June 26 - 28, 2006). ITICSE '06. ACM Press, New York, NY, 33-37.

[15] Sheard, J. 2004. Electronic learning communities: strategies for establishment and management. In Proceedings of the 9th Annual SIGCSE Conference on innovation and Technology in Computer Science Education (Leeds, United Kingdom, June 28 - 30, 2004). ITiCSE '04. ACM Press, New York, NY, 37-41. 